\title{
Sociodemographic, behavioral, and medical risk factors associated with visual impairment among older adults: a community-based pilot survey in Southern District of Hong Kong
}

Perseus Wing-Fu WONG, Jordy Kin-Pong LAU, Bonnie Nga-Kwan CHOY, Kendrick Co SHIH, Alex Lap-Ki NG, Ian Yat-Hin WONG and Jonathan Cheuk-Hung CHAN ${ }^{*}$ (i)

\begin{abstract}
Background: The last visual survey of older adults in Hong Kong was a district-level study in 2002, with no assessment of behavioral and medical risk factors for visual impairment $(\mathrm{VI})$. Our objectives were to determine the latest $\mathrm{VI}$ prevalence among older adults, significance of any spatial and temporal differences on the prevalence, and any associations of sociodemographic, behavioral and medical risk factors with VI from a multi-perspective analysis.

Methods: Community-based pilot survey of residents from a suburb of Hong Kong, aged $\geq 50$, using a standardized questionnaire, was conducted in 2016

Results: Of the 222 subjects, crude rates of bilateral and unilateral VI were 9.46 and 32.88\%, respectively, or corresponding age-and-gender-adjusted rates of 6.89 and 30.5\%. Older age and lower educational were associated with higher risk for unilateral VI, while older age, temporary housing, obesity and hyperlipidemia were associated with higher risk for bilateral VI. Smoking and alcohol-drinking status were not associated with unilateral or bilateral $\mathrm{VI}$. Relative changes in ORs of hypertension or educational level on unilateral or bilateral VI were $>10 \%$ after adjusting for age. Interaction term between hyperlipidemia and gender or obesity was significant for unilateral VI. Gender, hypertension and cataract were not associated with unilateral or bilateral VI in general population of pooled analysis but were identified as risk factors in specific subgroups of stratified analysis. Refractive error (myopia or hyperopia) was significantly associated with VI in the eye-level analysis after adjusting the inter-eye correlation.

*Correspondence: jonochan@hku.hk; jonnochan@yahoo.com Department of Ophthalmology, LKS Faculty of Medicine, University of Hong Kong, Room 301, Block B, Cyberport 4, Pok Fu Lam, Hong Kong

C C The Author(s). 2020 Open Access This article is licensed under a Creative Commons Attribution 4.0 International License, which permits use, sharing, adaptation, distribution and reproduction in any medium or format, as long as you give appropriate credit to the original author(s) and the source, provide a link to the Creative Commons licence, and indicate if changes were made. The images or other third party material in this article are included in the article's Creative Commons licence, unless indicated otherwise in a credit line to the material. If material is not included in the article's Creative Commons licence and your intended use is not permitted by statutory regulation or exceeds the permitted use, you will need to obtain permission directly from the copyright holder. To view a copy of this licence, visit http://creativecommons.org/licenses/by/4.0/. The Creative Commons Public Domain Dedication waiver (http://creativecommons.org/publicdomain/zero/1.0/) applies to the data made available in this article, unless otherwise stated in a credit line to the data. 
(Continued from previous page)

Conclusions: Sociodemographic and medical risk factors contributed to VI, but behavioral risk factors did not. Sociodemographic disparities of visual health existed. Age was the confounders of the VI-hypertension or VIeducational level relationships. Gender and obesity were more likely to have multiplicative effect on unilateral VI when combined with hyperlipidemia. Stratified analysis should be conducted to provide further insight into the risk factors for VI in specific populations. Uncorrected refractive error remains a significant cause of impaired vision. The spatial and temporal differences in bilateral VI prevalence from the previous local study indicates a territory-wide survey is needed to assess regional differences and overall prevalence of VI in Hong Kong.

Keywords: Visual impairment, Prevalence, Risk factors, Survey, Hong Kong, Disparities, Stratified analysis, Eye-level analysis, Interaction effect

\section{Introduction}

\section{Background}

Visual impairment (VI) is significantly associated with poor physical health, limitation, and disability [1, 2]. Previous studies have shown a correlation between the severity of VI and the incidence of falls, fractures, chronic diseases and mortality in the elderly [3-8]. Visually impaired people are more likely to have poorer social network, lower employment status, and mental health problems [9-11]. Using different scoring scales to measure and evaluate quality of life (QoL) have suggested that VI severity is negatively correlated with QoL scores [12-17]. Increased VI is also correlated with substantial health burden [18]. Elderly people with VI are more likely to require social support services and nursing home placement, $[19,20]$ and their community would also need to bear the associated medical cost and productivity loss [21, 22].

Socioeconomic factors can explain $69.4 \%$ of the global variations in the prevalence of moderate to severe VI and $76.3 \%$ of the global variations in prevalence of blindness [23]. Unfavorable socioeconomic status is associated with a higher prevalence of low vision and blindness in many countries [24-28]. Behavioral factors like smoking status and alcohol-drinking pattern were associated with VI among older adults, [29, 30] while biomarkers such as increased serum low-density lipoprotein (LDL), homocysteine, and being underweight were shown to be associated with blindness [31]. Thus, individual health is mutually determined by the biological, behavioral, cultural, social and environmental factors. A broader framework was required for analyzing visual health problems from biosocial and socio-behavioral perspectives [32].

\section{Rationales and objectives}

To our knowledge, there was no territory-wide visual health survey of older adults in Hong Kong but had been a district-level survey in 2002, in the Shatin District (a northern region of Hong Kong which is less densely populated than the main urban areas of Hong Kong
Island and Kowloon) [33]. We hypothesized that spatial (Shatin and Southern Districts) and temporal (2002 and 2016) differences on the prevalence of VI among older adults would be statistically significant at district-level of Hong Kong when compared our results with the previous survey in 2002.

In addition, the survey in 2002 only covered the sociodemographic characteristics of the subjects in statistical analysis, but did not measure the associations of behavioral and medical risk factors with VI. The Singapore Malays Eye Study was an example of examining the associations of sociodemographic, behavioral and medical risk factors with VI, which shown that older age, lower education, unemployment, being widowed, diabetes and hypertension were independently associated with bilateral VI [34]. We hypothesized that behavioral and medical risk factors would be associated with VI among older adults, other than sociodemographic characteristics.

Our primary objective was to estimate the prevalence of VI among older adults within Southern District (located on the southern part of Hong Kong Island), in order to examine the significance of spatial and temporal differences on the prevalence of VI at district-level of Hong Kong when compared our results with the survey in 2002 and then show the rationale of conducting a territory-wide survey throughout Hong Kong.

The secondary objective was to measure the associations of sociodemographic, behavioral and medical risk factors with VI among older adults, in order to review the visual health problems and identify the vulnerable groups for VI from biosocial and socio-behavioral perspectives. The findings of this pilot survey will be useful in evaluating the feasibility of a forthcoming 5-year eye screening programme, and designing future large-scale eye research surveys.

\section{Methods}

Ethics approval and informed consent

Ethics approval of this study was granted by the Institutional Review Board (IRB) and Ethics Committees (EC) 
of the Hong Kong University / Hospital Authority Hong Kong West Cluster (reference number: UW 15-160) on 16th March 2015. All subjects agreeing to participate in the study gave their written, informed consent prior to the administration of any eye assessment or questionnaire.

\section{Study area and sampling}

This community-based, cross-sectional, pilot survey was conducted at $\mathrm{Chi} \mathrm{Fu}$, which is a suburb randomly selected from the 17 possible District Council Constituency Areas (DCCAs) of the Southern District of Hong Kong. According to the 2016 Population Bycensus, Chi Fu had an estimated population of 15,784 and domestic households of 5437. The residents aged 50 and above for this area was 6427 (46.52\% males, $53.48 \%$ females) [35]. On average, its residents had a higher educational level, household income, and proportion living in private housing (rather than public housing) than the mean for the entire Southern District, Shatin District and Hong Kong. (Supplementary file 1, Table 6).

Invitation letters (in Chinese) for a free eye assessment and visual health survey, to be conducted at the local community hall, were sent to all registered households within the study area (i.e. Chi Fu DCCA) at the same time to ensure that all residents would have the same opportunity to get the information and participate in our survey. On a first-come-first-served basis (i.e. convenience sampling which is common in pilot study), residents who were interested to participate responded by calling back to make an appointment at a designated time for a free eye consultation with an ophthalmologist, during which, trained research assistants explained the details of the study and distributed the questionnaire (Supplementary files 10, 11) for their own completion. The targeted study population were local Chinese residents aged 50 and above, with no extra inclusion and exclusion criteria. The survey fieldwork was carried out from the 11th to the 28th, January 2016.

\section{Measurements}

At the study site, optometrists measured the presenting visual acuity (VA) for each eye of the subject, using a Logarithm of the Minimum Angle of Resolution (logMAR) visual acuity chart at a distance of $3 \mathrm{~m}$. If none of the large optotype on the highest line could be identified, VA was then assessed for counting fingers, hand motion, and presence or absence of light perception, in that order. Refractive error was measured by subjective refraction. Experienced ophthalmic assistants measured intraocular pressure and performed autorefraction using NIDEK Tonoref II. Slip-lamp examination of eyelids, ocular surface and anterior segment using Topcon SL
701 with DC4, as well as optical coherence tomography (OCT) scan using the Cirrus-5000 SD-OCT were performed by ophthalmologists, to examine the fundus without dilating the pupil and measure the macula and peripapillary retinal nerve fiber layer (RNFL) thickness and volume. We did not test the visual field defects, but measured the blood pressure, ankle-brachial index (ABI), body weight, and height of the subjects.

A structured and self-administrated questionnaire in Chinese was used to collect data on sociodemographic, behavioral, and medical characteristics. Sociodemographic and behavioral information covered age, gender, type of housing, educational level, marital status, employment status, monthly household income, smoking and alcohol-drinking habits. Subjects were inquired for any history of chronic medical conditions like diabetes mellitus (DM), hypertension, and hyperlipidemia, as well as three common eye diseases including age-related macular degeneration (AMD), cataract, and glaucoma.

\section{Operational definitions}

We used the World Health Organization (WHO) criteria to define blindness as presenting VA of $<3 / 60(\log M A R$ $>1.3$ ) and low vision as presenting VA of $<6 / 18$ and $\geq 3$ / 60 ( $\log M A R>0.5$ and $\leq 1.3)$, without considering the visual fields [36]. Bilateral VI included both blindness and low vision in the better-seeing eye. For providing further insight into unilateral VI, we presented the results of blindness and low vision with the same definition in terms of the worse-seeing eye [34, 37]. Myopia and hyperopia were defined as spherical equivalent refractions of $<-0.50$ diopter or $>+0.50$ diopter, respectively [38]. Body Mass Index (BMI) is equivalent to the weight (in kilograms) over height squared (in centimeters) and was categorized into underweight $(<18.5)$, normal weight (18.5-22.9), overweight (23-24.9), and obesity ( $\geq 25)$ [39-41]. Ankle-brachial index (ABI) was categorized into blockage $(<1.0)$, normal (1.0-1.4), and rigid arteries $(>1.4)$ [42]. Blood pressure was categorized into low $(\leq 90 / 60)$, normal $(>90 / 60$ and $<120 / 80)$, prehigh (120/80-139/89), and high $(\geq 140 / 90)[43,44]$.

\section{Data analysis}

For descriptive data analysis, median with interquartile range (IQR) was used to summarize continuous variables, whilst frequencies and percentages were used to summarize categorical variables. Crude, ageand-gender-adjusted, age-specific and gender-specific prevalence estimates of low vision, blindness, bilateral and unilateral VI were expressed in percentage with 95\% confidence intervals (CIs). Relative changes in odds ratios (ORs) were calculated to measure the magnitude of confounding and examine the 
confounding effect of age on the associations of VI with obesity, hypertension, hyperlipidemia and educational level. Multiplicative interaction model and stratified analysis were done to examine the effect modification between independent variables on the risk for unilateral and bilateral VI. Univariate and multivariate logistic models with backward stepwise method were conducted to examine the associations between VI and independent variables at subject-level. Generalized linear mixed effects models (GLMM) were used to investigate the associations of VI with eye examination results at eye-level analysis after adjusting the inter-eye correlation. Crude and adjusted odds ratios (CORs and AORs) with 95\% CIs were calculated to show the strength of associations. A $p$-value of $<0.05$ was considered statistically significant. We included records with incomplete data in analyses and used multiple imputation method to handle missing data by creating 2000 multiple datasets and combining estimates from imputed datasets to obtain the overall estimate, based on the assumption of missing at random [45, 46]. The database was maintained and managed using Microsoft Excel 2016 (Microsoft Corporation, Redmond, WA, USA). All statistical analysis were performed using $\mathrm{R}$ package version 3.5.1 (R Development Core Team, 2018) [47].

\section{Results}

\section{Characteristics of subjects}

A total of 222 subjects, median age 67 years (IQR: 6172 ), agreed to participate in the study, including 87 males (39.19\%) and 135 females (60.81\%). The majority was aged between 60 and 69 (49.55\%). Most of them had completed secondary education (51.35\%) and lived in private housing $(94.14 \%)$. They were predominantly married (85.14\%) and not working (89.64\%). Nearly threefourths $(75.22 \%)$ had monthly household income below $\$ 25,000$. The self-reported prevalence of DM, hypertension, hyperlipidemia, AMD, cataract and glaucoma were $12.61,39.64,15.32,4.05,22.97$ and $2.70 \%$, respectively. The proportions of current and past smokers were 1.35 and $3.6 \%$, respectively, whilst those of current and past alcohol-drinkers were 17.12 and $1.8 \%$, respectively. (Supplementary file 2. Table 7).

\section{Descriptive and univariate logistic analysis}

The numbers of right eye and left eye with VI (low vision or blindness) were 46 and 48 respectively whilst the cases of bilateral and unilateral VI were 21 and 73 respectively. The crude rates of bilateral and unilateral VI were 9.46 and $32.88 \%$ respectively while the age-and-gender-adjusted rates were 6.89 and $30.5 \%$ respectively. Age-specific rates of 59-59, 60-69, $70-79$ and $\geq 80$ were $17.5,31.82,37.74$ and $57.89 \%$ respectively for unilateral VI, as well as $0,9.09,13.21$ and $21.05 \%$ respectively for bilateral VI. Genderspecific rates of males and females were 34.48 and $31.85 \%$ respectively for unilateral VI, as well as 12.64 and $7.41 \%$ respectively for bilateral VI. (Supplementary file 3 . Table 8 ).

Univariate logistic regression results showed the significant associations of unilateral or bilateral VI with older age, low educational level and obesity. Household income and having a history of hypertension were significantly associated with unilateral VI, while living in temporary housing and having a history of hyperlipidemia were significantly associated with bilateral VI. (Supplementary file 4. Table 9) We did not find any significant crude association of unilateral or bilateral VI with current or past smoking or alcoholdrinking, but found that current or past smoking was associated with being obese and having a history of hypertension. (Supplementary file 5. Table 10).

\section{Multivariate logistic analysis}

Multivariate logistic regression results with backward stepwise method in Table 1 noted that subjects with older age (AOR 1.04; 95\% CI 1.00-1.09) and educational level higher than secondary with either non-degree (AOR 0.28; 95\% CI 0.09-0.80) or degree tertiary education (AOR 0.29 ; $95 \%$ CI $0.08-0.89$ ), were significantly associated with unilateral VI. In addition, subjects with older age (AOR 1.08; 95\% CI 1.02-1.15), being obese (AOR 4.00; 95\% CI 1.49-11.41), having a history of hyperlipidemia (AOR 3.60; 95\% CI 1.13-10.97), and living in temporary housing (AOR 8.26; 95\% CI 1.8134.92 ), were significantly associated with bilateral VI. Older age was likely to be common variable contributing to unilateral or bilateral VI. Our results did not find any significant adjusted association of smoking and alcoholdrinking status with unilateral or bilateral VI.

\section{Confounding, effect modification and stratified analysis}

The relative changes in ORs of exposures on unilateral or bilateral VI after adjusting for age were calculated to measure the magnitude of confounding in Table 2. After adjusting for age, for unilateral VI, ORs of having a history of hypertension decreased from $1.97(1.12-3.51)$ to 1.52 (0.83-2.79), having non-degree tertiary education increased from $0.2(0.07-0.56)$ to $0.26(0.08-0.72)$, and having degree tertiary education increased from 0.21 $(0.06-0.61)$ to $0.29(0.08-0.86)$, with the effect of age remaining significant. Similarly, for bilateral VI, ORs of having secondary education increased from 0.19 (0.06$0.53)$ to $0.25(0.08-0.74)$. Since the corresponding relative changes in ORs were $22.84,30,38$ and $31.58 \%$, we noted that age was the confounders of the unilateral VIhypertension, unilateral VI-educational level and 
Table 1 Epidemiologic factors associated with visual impairment by the 222 respondents from a southern suburb of Hong Kong in January 2016: Multivariate logistic regression

\begin{tabular}{|c|c|c|c|c|c|}
\hline \multirow[t]{2}{*}{ Variables } & \multicolumn{2}{|c|}{ Unilateral Visual Impairment } & \multicolumn{3}{|c|}{ Bilateral Visual Impairment } \\
\hline & AOR $(95 \% \mathrm{Cl})$ & $p$-value & AOR $(95 \% \mathrm{Cl})$ & $p$-value & \\
\hline Age (Years) & $1.04(1.00-1.09)$ & $0.031^{* *}$ & $1.08(1.02-1.15)$ & $0.011^{* *}$ & \\
\hline \multicolumn{6}{|l|}{ Educational level: } \\
\hline Primary level or below (ref) & 1.00 & - & & & \\
\hline Secondary level & $0.54(0.26-1.13)$ & 0.103 & & & \\
\hline Non-degree level & $0.28(0.09-0.80)$ & $0.022^{* *}$ & & & \\
\hline Degree level & $0.29(0.08-0.89)$ & $0.039^{* *}$ & & & \\
\hline \multicolumn{6}{|l|}{ Housing type: } \\
\hline Private housing (ref) & & & 1.00 & - & \\
\hline Temporary housing & & & $8.26(1.81-34.92)$ & $0.004^{* * *}$ & \\
\hline \multicolumn{6}{|l|}{ Obesity (BMI $\geq 25$ ) } \\
\hline No (Ref) & 1.00 & - & 1.00 & - & \\
\hline Yes & $1.86(0.99-3.51)$ & $0.053^{*}$ & $4.00(1.49-11.41)$ & 0.007 & $* * *$ \\
\hline \multicolumn{6}{|l|}{ Hyperlipidemia } \\
\hline No (Ref) & & & 1.00 & - & \\
\hline Yes & & & $3.60(1.13-10.97)$ & $0.025^{* *}$ & \\
\hline \multicolumn{6}{|l|}{ Glaucoma } \\
\hline No (Ref) & 1.00 & - & & & \\
\hline Yes & $4.11(0.69-32.92)$ & 0.132 & & & \\
\hline
\end{tabular}

AOR adjusted odds ratio, $\mathrm{Cl}$ confidence interval

${ }^{*} p$-value $<0.1 ;{ }^{* *} p$-value $<0.05 ;{ }^{* * *} p$-value $<0.01$

bilateral VI-educational level relationships due to a relative change of $>10 \%$ in the ORs of having a history of hypertension or higher educational level on unilateral or bilateral VI after adjusting for age.

In Table 3, we examined whether hyperlipidemia interacts with age, gender, obesity, hypertension or cataract on the risk for unilateral or bilateral VI. For unilateral $\mathrm{VI}$, the interaction term between:

1. gender and a history of hyperlipidemia was significant (OR 0.14; 95\% CI 0.02-0.71), implying that the risk effect of having a history of hyperlipidemia in females was significantly lower than in males.

2. obesity and a history of hyperlipidemia was significant (OR 17.64; 95\% CI 2.82-164.9), implying that the risk effect of having a history of hyperlipidemia in obese subjects was significantly higher than in non-obese subjects.

Gender and obesity were likely to modify the association between hyperlipidemia and the risk for unilateral VI, so combining them would allow for a more accurate and greater effect than the sum of their individual effects. No significant interaction term was found for bilateral VI. We have summarized the non-significant results of examining the effect modification between variables on the risk for unilateral or bilateral VI. (Supplementary files 6-9. Tables 11, 12, 13, 14).

ORs, stratified by gender, obesity, hypertension, hyperlipidemia and cataract, were shown in Table 4. For unilateral VI, in stratified analysis, we found that:

1. stratified by gender, males with a history of hyperlipidemia (OR 3.55; 95\% CI 1.25-10.51) and females with obesity (OR 2.44; 95\% CI 1.09-5.48) suffered higher risk.

2. stratified by obesity, obese subjects having a history of hyperlipidemia (OR 9.21; 95\% CI 2.15-64.1) and non-obese subjects having a history of hypertension (OR 2.18; 95\% CI 1.04-4.53) suffered higher risk.

3. stratified by a history of hyperlipidemia, among those having a history, females (OR 0.18; 95\% CI 0.03-0.79) suffered lower risk but subjects being obese (OR 22.5; 95\% CI 4.11-192.5) and having a history of cataract (OR 6.75; 95\% CI 1.25-53.54) suffered higher risk.

4. stratified by a history of cataract, subjects with a history of hyperlipidemia (OR 5.6; 95\% CI 1.1341.57) among those with a history and obese subjects (OR 2.08; 95\% CI 1.05-4.14) among those without a history, suffered higher risk. 
Table 2 Magnitude of confounding of obesity, hypertension, hyperlipidemia and educational levels on visual impairment after adjusting the age

\begin{tabular}{|c|c|c|c|c|}
\hline & \multicolumn{2}{|c|}{ Unilateral Visual Impairment } & \multicolumn{2}{|c|}{ Bilateral Visual Impairment } \\
\hline & Estimate $(95 \% \mathrm{Cl})$ & p-value & Estimate $(95 \% \mathrm{Cl})$ & $p$-value \\
\hline \multicolumn{5}{|l|}{ A } \\
\hline Association of age with $\mathrm{VI}$ & $1.06(1.02-1.10)$ & $0.001^{* * *}$ & $1.09(1.03-1.15)$ & $0.003^{* * *}$ \\
\hline Association of age with obesity & $1.03(0.99-1.06)$ & 0.163 & $1.03(0.99-1.06)$ & 0.163 \\
\hline Association of obesity with $\mathrm{Vl}$ & $2.00(1.09-3.63)$ & $0.024^{* *}$ & $3.63(1.46-9.36)$ & $0.006^{* * *}$ \\
\hline \multicolumn{5}{|l|}{ Association of age and obesity with $\mathrm{Vl}$} \\
\hline -Age & $1.06(1.02-1.10)$ & $0.002^{* * *}$ & $1.09(1.03-1.16)$ & $0.003^{* * *}$ \\
\hline -Obesity & $1.89(1.02-3.49)$ & $0.041^{* *}$ & $3.58(1.40-9.52)$ & $0.008^{* * *}$ \\
\hline \multicolumn{5}{|c|}{ Magnitude of confounding: relative change in OR of obesity on VI after adjusting the age } \\
\hline - Obesity & $5.50 \%$ & $(<10 \%)$ & $1.38 \%$ & $(<10 \%)$ \\
\hline \multicolumn{5}{|l|}{ B } \\
\hline Association of age with $\mathrm{VI}$ & $1.06(1.02-1.10)$ & $0.001^{* * *}$ & $1.09(1.03-1.15)$ & $0.003^{* * *}$ \\
\hline Association of age with history of hypertension & $1.10(1.06-1.14)$ & $<0.001^{* * *}$ & $1.10(1.06-1.14)$ & $<0.001^{* * *}$ \\
\hline Association of history of hypertension with $\mathrm{VI}$ & $1.97(1.12-3.51)$ & $0.019^{* *}$ & $2.19(0.89-5.61)$ & $0.091^{*}$ \\
\hline \multicolumn{5}{|l|}{ Association of age and history of hypertension with $\mathrm{VI}$} \\
\hline -Age & $1.05(1.01-1.09)$ & $0.002^{* * *}$ & $1.08(1.02-1.15)$ & $0.008^{* * *}$ \\
\hline -History of hypertension & $1.52(0.83-2.79)$ & $0.008^{* *}$ & $1.48(0.56-3.95)$ & 0.426 \\
\hline \multicolumn{5}{|c|}{ Magnitude of confounding: relative change in OR of history of hypertension on VI after adjusting the age } \\
\hline - History of hypertension & $22.84 \%$ & $(>10 \%)$ & $32.42 \%$ & $(>10 \%)$ \\
\hline \multicolumn{5}{|l|}{ C } \\
\hline Association of age with $\mathrm{VI}$ & $1.06(1.02-1.10)$ & $0.001^{* * *}$ & $1.09(1.03-1.15)$ & $0.003^{* * *}$ \\
\hline Association of age with history of hyperlipidemia & $1.04(0.99-1.08)$ & 0.121 & $1.04(0.99-1.08)$ & 0.121 \\
\hline Association of history of hyperlipidemia with VI & $1.53(0.71-3.22)$ & 0.266 & $3.22(1.13-8.51)$ & $0.021^{* *}$ \\
\hline \multicolumn{5}{|c|}{ Association of age and history of hyperlipidemia with VI } \\
\hline -Age & $1.06(1.02-1.10)$ & $0.002^{* * *}$ & $1.09(1.03-1.16)$ & $0.004^{* * *}$ \\
\hline -History of hyperlipidemia & $1.37(0.63-2.93)$ & 0.419 & $2.96(1.01-8.06)$ & $0.038^{* *}$ \\
\hline \multicolumn{5}{|c|}{ Magnitude of confounding: relative change in OR of history of hyperlipidemia on $\mathrm{VI}$ after adjusting the age } \\
\hline - History of hyperlipidemia & $10.46 \%$ & $(\approx 10 \%)$ & $8.07 \%$ & $(<10 \%)$ \\
\hline \multicolumn{5}{|l|}{ D } \\
\hline Association of age with $\mathrm{VI}$ & $1.06(1.02-1.10)$ & $0.001^{* * *}$ & $1.09(1.03-1.15)$ & $0.003^{* * *}$ \\
\hline Association of age with educational level & $0.91(0.88-0.95)$ & $<0.001^{* * *}$ & $0.91(0.88-0.95)$ & $<0.001^{* * *}$ \\
\hline \multicolumn{5}{|l|}{ Association of educational level with $\mathrm{VI}$} \\
\hline - Secondary level & $0.44(0.22-0.88)$ & $0.020^{* *}$ & $0.19(0.06-0.53)$ & $0.002^{* * *}$ \\
\hline - Non-degree level & $0.20(0.07-0.56)$ & $0.003^{* * *}$ & $0.22(0.03-0.89)$ & $0.058^{*}$ \\
\hline - Degree level & $0.21(0.06-0.61)$ & $0.006^{* * *}$ & $0.27(0.04-1.11)$ & 0.106 \\
\hline \multicolumn{5}{|l|}{ Association of age and educational level with VI } \\
\hline -Age & $1.05(1.01-1.09)$ & $0.018^{* *}$ & $1.07(1.01-1.14)$ & $0.030^{* *}$ \\
\hline \multicolumn{5}{|l|}{-Educational level } \\
\hline - Secondary level & $0.55(0.27-1.13)$ & 0.101 & $0.25(0.08-0.74)$ & $0.014^{* *}$ \\
\hline - Non-degree level & $0.26(0.08-0.72)$ & $0.013^{* *}$ & $0.32(0.05-1.40)$ & 0.169 \\
\hline - Degree level & $0.29(0.08-0.86)$ & $0.034^{* *}$ & $0.44(0.06-2.02)$ & 0.333 \\
\hline \multicolumn{5}{|c|}{ Magnitude of confounding: relative change in OR of educational level on VI after adjusting the age } \\
\hline - Secondary level & $25 \%$ & $(>10 \%)$ & $31.58 \%$ & $(>10 \%)$ \\
\hline
\end{tabular}


Table 2 Magnitude of confounding of obesity, hypertension, hyperlipidemia and educational levels on visual impairment after adjusting the age (Continued)

\begin{tabular}{|c|c|c|c|c|}
\hline & \multicolumn{2}{|c|}{ Unilateral Visual Impairment } & \multicolumn{2}{|c|}{ Bilateral Visual Impairment } \\
\hline & Estimate $(95 \% \mathrm{Cl})$ & p-value & Estimate $(95 \% \mathrm{Cl})$ & $p$-value \\
\hline - Non-degree level & $30 \%$ & $(>10 \%)$ & $45.45 \%$ & $(>10 \%)$ \\
\hline - Degree level & $38 \%$ & $(>10 \%)$ & $62.96 \%$ & $(>10 \%)$ \\
\hline
\end{tabular}

$\mathrm{Cl}$ confidence interval, $\mathrm{VI}$ visual impairment

${ }^{*} p$-value $<0.1 ;{ }^{* *} p$-value $<0.05 ;{ }^{* * *} p$-value $<0.01$

For bilateral VI, our results of stratified analysis showed that:

1. stratified by gender, males with obesity (OR 5.78; 95\% CI 1.52-28.18), a history of hyperlipidemia (OR 5.82; 95\% CI 1.54-23.11) and cataract (OR 4.04; 95\% CI 1.03-15.49) suffered higher risk.

2. stratified by obesity, obese subjects having a history of hyperlipidemia (OR 4.8; 95\% CI 1.1619.81) and non-obese subjects having a history of cataract (OR 4.32; 95\% CI 1.08-18.33) suffered higher risk.

3. stratified by a history of hypertension, among those having a history, subjects being obese (OR 4.35; 95\% CI 1.19-20.82) and having a history of hyperlipidemia (OR 4.07; 95\% CI 1.13-14.82), suffered higher risk.

4. stratified by a history of hyperlipidemia, obese subjects (OR 7.14; 95\% CI 1.24-58.63), among those having a history, suffered higher risk.

5. stratified by a history of cataract, obese subjects (OR 5.83; 95\% CI 1.8-22.42), among those not having a history, suffered higher risk.

\section{Eye-level analysis}

On analysis of individual eyes, in Table 5, the proportions of myopia or hyperopia, abnormal or suspicious optic disc, and abnormal or undetermined macular appearance were $78.38,13.51,8.56$ and $74.77 \%, 11.71$, $9.01 \%$, for the right and left eyes, respectively. VI was

Table 3 Multiplicative interaction model for observing whether hyperlipidemia interacts with age, gender, obesity, hypertension or cataract on the risk for unilateral and bilateral VI

\begin{tabular}{|c|c|c|c|c|}
\hline & \multicolumn{2}{|l|}{ Unilateral VI } & \multicolumn{2}{|l|}{ Bilateral VI } \\
\hline & Est. $(95 \% \mathrm{Cl})$ & p-value & Est. $(95 \% \mathrm{Cl})$ & $p$-value \\
\hline \multicolumn{5}{|l|}{ Model A } \\
\hline History of hyperlipidemia & $0.00(0.00-18.45)$ & 0.245 & $0.01(0.00-304.4)$ & 0.413 \\
\hline Age & $1.05(1.01-1.09)$ & $0.012^{* *}$ & $1.07(1.00-1.14)$ & $0.037^{* *}$ \\
\hline History of hyperlipidemia: Age & $1.09(0.96-1.26)$ & 0.217 & $1.08(0.94-1.28)$ & 0.308 \\
\hline \multicolumn{5}{|l|}{ Model B } \\
\hline History of hyperlipidemia & $3.55(1.25-10.51)$ & $0.019^{* *}$ & $5.82(1.54-23.11)$ & $0.009^{* * *}$ \\
\hline Gender & $1.29(0.68-2.51)$ & 0.444 & $1.02(0.34-3.45)$ & 0.971 \\
\hline History of hyperlipidemia: Gender & $0.14(0.02-0.71)$ & $0.023^{* *}$ & $0.15(0.01-1.45)$ & 0.142 \\
\hline \multicolumn{5}{|l|}{ Model C } \\
\hline History of hyperlipidemia & $0.52(0.14-1.51)$ & 0.266 & $1.81(0.26-8.16)$ & 0.477 \\
\hline Obesity & $1.28(0.65-2.48)$ & 0.476 & $2.70(0.88-8.30)$ & $0.077^{*}$ \\
\hline History of hyperlipidemia: Obesity & $17.64(2.82-164.9)$ & $0.005^{* * *}$ & $2.64(0.33-27.57)$ & 0.376 \\
\hline \multicolumn{5}{|l|}{ Model D } \\
\hline History of hyperlipidemia & $0.80(0.17-2.81)$ & 0.746 & $1.18(0.06-7.26)$ & 0.883 \\
\hline History of hypertension & $1.69(0.90-3.19)$ & 0.104 & $1.39(0.44-4.18)$ & 0.559 \\
\hline History of hyperlipidemia: History of hypertension & $2.17(0.43-13.14)$ & 0.365 & $3.45(0.36-81.31)$ & 0.332 \\
\hline \multicolumn{5}{|l|}{ Model E } \\
\hline History of hyperlipidemia & $1.02(0.39-2.46)$ & 0.965 & $2.75(0.70-9.26)$ & 0.116 \\
\hline History of cataract & $1.23(0.59-2.50)$ & 0.574 & $1.99(0.58-6.12)$ & 0.242 \\
\hline History of hyperlipidemia: History of cataract & $5.49(0.87-48.40)$ & $0.086^{*}$ & $1.66(0.19-14.45)$ & 0.640 \\
\hline
\end{tabular}

Cl confidence interval, Est. estimate, $V I$ visual impairment

${ }^{*} p$-value $<0.1$; ${ }^{* *} p$-value $<0.05$; ${ }^{* * *} p$-value $<0.01$ 
Table 4 Stratified analysis of odds ratios of gender, obesity, hypertension, hyperlipidemia and cataract on unilateral and bilateral visual impairment among 222 subjects

\begin{tabular}{|c|c|c|c|c|c|c|c|c|c|}
\hline & & \multicolumn{2}{|l|}{$\begin{array}{l}\text { Unilateral Visual } \\
\text { Impairment }\end{array}$} & \multicolumn{2}{|l|}{$\begin{array}{l}\text { Bilateral Visual } \\
\text { Impairment }\end{array}$} & \multicolumn{2}{|l|}{$\begin{array}{l}\text { Unilateral Visual } \\
\text { Impairment }\end{array}$} & \multicolumn{2}{|l|}{$\begin{array}{l}\text { Bilateral Visual } \\
\text { Impairment }\end{array}$} \\
\hline & & $\begin{array}{l}\text { Estimate }(95 \% \\
\mathrm{Cl})\end{array}$ & $p$-value & $\begin{array}{l}\text { Estimate }(95 \% \\
\mathrm{Cl})\end{array}$ & $p$-value & $\begin{array}{l}\text { Estimate }(95 \% \\
\mathrm{Cl})\end{array}$ & $\begin{array}{l}p- \\
\text { value }\end{array}$ & $\begin{array}{l}\text { Estimate }(95 \% \\
\mathrm{Cl})\end{array}$ & $p$-value \\
\hline $\bar{A}$ & Stratified by gender & Male & & & & Female & & & \\
\hline i & Obesity & $1.53(0.61-3.81)$ & 0.359 & $5.78(1.52-28.18)$ & $0.015^{* *}$ & $2.44(1.09-5.48)$ & $0.030^{* *}$ & $2.11(0.51-7.89)$ & 0.271 \\
\hline ii & History of hypertension & $2.21(0.90-5.62)$ & $0.087^{*}$ & $2.96(0.79-14.32)$ & 0.129 & $1.83(0.85-3.90)$ & 0.118 & $1.42(0.35-5.24)$ & 0.605 \\
\hline iii & History of hyperlipidemia & $3.55(1.25-10.51)$ & $0.019^{* *}$ & $5.82(1.54-23.11)$ & $0.009^{* * *}$ & $0.50(0.11-1.68)$ & 0.304 & $0.88(0.05-5.23)$ & 0.908 \\
\hline iv & History of cataract & $2.29(0.79-6.68)$ & 0.125 & $4.04(1.03-15.49)$ & $0.040^{* *}$ & $1.31(0.56-2.96)$ & 0.523 & $1.36(0.28-5.22)$ & 0.672 \\
\hline B & Stratified by obesity & Obesity & & & & Non-obesity & & & \\
\hline 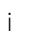 & Gender & $1.30(0.49-3.48)$ & 0.599 & $0.40(0.10-1.43)$ & 0.172 & $0.82(0.40-1.70)$ & 0.580 & $1.09(0.28-5.35)$ & 0.901 \\
\hline ii & History of hypertension & $1.12(0.41-3.06)$ & 0.830 & $2.23(0.59-10.87)$ & 0.267 & $2.18(1.04-4.53)$ & $0.037^{* *}$ & $1.13(0.23-4.50)$ & 0.864 \\
\hline iii & History of hyperlipidemia & $9.21(2.15-64.10)$ & $0.007^{* * *}$ & $4.80(1.16-19.81)$ & $0.028^{* *}$ & $0.52(0.14-1.51)$ & 0.266 & $1.81(0.26-8.16)$ & 0.477 \\
\hline iv & History of cataract & $1.64(0.48-5.76)$ & 0.424 & $1.47(0.29-6.02)$ & 0.611 & $1.71(0.77-3.71)$ & 0.176 & $4.32(1.08-18.33)$ & $0.037^{* *}$ \\
\hline C & $\begin{array}{l}\text { Stratified by history of } \\
\text { hypertension }\end{array}$ & Having a history & & & & No history & & & \\
\hline i & Gender & $0.91(0.39-2.13)$ & 0.829 & $0.45(0.11-1.56)$ & 0.222 & $1.10(0.49-2.59)$ & 0.818 & $0.94(0.24-4.64)$ & 0.934 \\
\hline ii & Obesity & $1.25(0.53-2.94)$ & 0.608 & $4.35(1.19-20.82)$ & $0.037^{* *}$ & $2.43(0.98-5.97)$ & $0.052^{*}$ & $2.22(0.44-9.08)$ & 0.284 \\
\hline iii & History of hyperlipidemia & $1.73(0.64-4.73)$ & 0.274 & $4.07(1.13-14.82)$ & $0.030^{* *}$ & $0.80(0.17-2.81)$ & 0.746 & $1.18(0.06-7.26)$ & 0.883 \\
\hline iv & History of cataract & $1.99(0.81-5.02)$ & 0.137 & $2.45(0.70-8.67)$ & 0.154 & $0.95(0.32-2.54)$ & 0.926 & $1.41(0.20-6.36)$ & 0.678 \\
\hline $\mathrm{D}$ & $\begin{array}{l}\text { Stratified by history of } \\
\text { hyperlipidemia }\end{array}$ & Having a history & & & & No history & & & \\
\hline i & Gender & $0.18(0.03-0.79)$ & $0.032^{* *}$ & $0.15(0.01-1.08)$ & 0.104 & $1.29(0.68-2.51)$ & 0.444 & $1.02(0.34-3.45)$ & 0.971 \\
\hline ii & Obesity & $\begin{array}{l}22.50(4.11- \\
192.5)\end{array}$ & $0.001^{* * *}$ & $7.14(1.24-58.63)$ & $0.038^{* *}$ & $1.28(0.65-2.48)$ & 0.476 & $2.70(0.88-8.30)$ & $0.077^{*}$ \\
\hline iii & History of hypertension & $3.67(0.84-20.04)$ & 0.100 & $4.80(0.69-97.27)$ & 0.172 & $1.69(0.90-3.19)$ & 0.104 & $1.39(0.44-4.18)$ & 0.559 \\
\hline iv & History of cataract & $6.75(1.25-53.54)$ & $0.038^{* *}$ & $3.30(0.52-20.41)$ & 0.190 & $1.23(0.59-2.50)$ & 0.574 & $1.99(0.58-6.12)$ & 0.242 \\
\hline $\mathrm{E}$ & Stratified by cataract & Having a history & & & & No history & & & \\
\hline i & Gender & $0.57(0.18-1.84)$ & 0.346 & $0.26(0.05-1.22)$ & $0.093^{*}$ & $1.00(0.52-1.95)$ & 0.995 & $0.77(0.25-2.50)$ & 0.658 \\
\hline ii & Obesity & $2.00(0.56-7.40)$ & 0.286 & $1.98(0.36-9.62)$ & 0.402 & $2.08(1.05-4.14)$ & $0.036^{* *}$ & $5.83(1.80-22.42)$ & $0.005^{* * *}$ \\
\hline iii & History of hypertension & $3.27(1.03-11.40)$ & $0.051^{*}$ & $2.86(0.58-21.07)$ & 0.227 & $1.56(0.79-3.06)$ & 0.192 & $1.65(0.51-5.21)$ & 0.388 \\
\hline iv & History of hyperlipidemia & $5.60(1.13-41.57)$ & $0.049^{* *}$ & $4.56(0.76-25.60)$ & $0.082^{*}$ & $1.02(0.39-2.46)$ & 0.965 & $2.75(0.70-9.26)$ & 0.116 \\
\hline
\end{tabular}

Cl confidence interval

${ }^{*} p$-value $<0.1 ; * *$-value $<0.05 ; * * *$-value $<0.01$

significantly associated with myopia or hyperopia (OR 6.69; 95\% CI 2.07-21.60) and marginally associated with abnormal or undetermined macular appearance (OR 3.02; 95\% CI 0.92-9.94) after adjusting the inter-eye correlation, but was not statistically associated with abnormal or suspicious optic disc. In the GLMM model for the association of VI with myopia or hyperopia, the variance estimates for random effects and intra-class correlation were 4.02 and 0.55 respectively to account for inter-eye correlation in outcome by adding a random effect.

\section{Discussion}

The previous Hong Kong survey in the Shatin District by Lau et al. in 2002 found that $41.3 \%$ of the sampled population $\geq 60$ had unilateral VI and 19.5\% had bilateral VI. Our estimated age-and-sex-adjusted rates of subjects aged $\geq 60$ in the Southern District in 2016 were 37.76\% (95\% CI, 28.76-48.69) for unilateral VI and 12.3\% (95\% CI, 7.39-19.24) for bilateral VI. For comparison, our results noted lower rate of bilateral VI, probably because the population composition of the two studies was different from the spatial (Shatin and Southern Districts) and temporal (2002 and 2016) perspectives of Hong Kong.

Our findings showed that sociodemographic disparities of visual health existed among our subjects. Chi $\mathrm{Fu}$ is generally considered a middle-class area in Hong Kong, but residents with older age, lower educational level, and 
Table 5 Associations between eye examination results and visual impairment at the eye-level analysis

\begin{tabular}{|c|c|c|c|c|}
\hline & \multicolumn{2}{|c|}{ Descriptive statistics } & \multicolumn{2}{|c|}{ Generalized linear mixed models } \\
\hline & \multicolumn{2}{|c|}{ Eye examination results } & \multicolumn{2}{|c|}{ Associations of VI with eye examination results } \\
\hline & $\begin{array}{l}\text { Right eye } \\
(n=222)\end{array}$ & $\begin{array}{l}\text { Left eye } \\
(n=222)\end{array}$ & Estimate $(95 \% \mathrm{Cl})$ & $p$-value \\
\hline \multicolumn{5}{|l|}{ Myopia or hyperopia } \\
\hline No (Ref) & $48(21.62)$ & $56(25.23)$ & 1.00 & - \\
\hline Yes & $174(78.38)$ & $166(74.77)$ & $6.69(2.07-21.60)$ & $0.001^{* * *}$ \\
\hline \multicolumn{5}{|l|}{ Optic disc } \\
\hline Normal cases (ref) & $192(86.49)$ & $196(88.29)$ & 1.00 & - \\
\hline Abnormal or suspicious cases & $30(13.51)$ & $26(11.71)$ & $0.81(0.29-2.29)$ & 0.697 \\
\hline \multicolumn{5}{|l|}{ Macula } \\
\hline Normal cases (ref) & $203(91.44)$ & $202(81.98)$ & 1.00 & - \\
\hline Abnormal or undetermined cases & $19(8.56)$ & $20(9.01)$ & $3.02(0.92-9.94)$ & $0.069^{*}$ \\
\hline
\end{tabular}

$\mathrm{Cl}$ confidence interval, $\mathrm{VI}$ visual impairment

${ }^{*} p$-value $<0.1 ;{ }^{* *} p$-value $<0.05 ;{ }^{* * *} p$-value $<0.01$

living in temporary housing still had a higher risk for unilateral or bilateral VI. We did not find any significant association of VI with gender, marital status, employment status and household income. Previous studies in eastern China, Singapore and Korea found, in addition to older age and lower educational level, that being unemployed, separated, or females were independent risk factors for VI [34, 48, 49]. However, the associations of VI with gender, marital status and employment status have not been shown in other studies from southern India and Taiwan $[50,51]$.

In addition, we investigated the associations of VI with behavioral and medical risk factors. The results did not support any significant association of VI with smoking or alcohol-drinking histories but showed the significant correlation between bilateral VI and obesity or hyperlipidemia. Previous study showed that the association of VI with obesity may be bidirectional rather than unidirectional [52]. Obesity may have an indirect negative effect on VI due to the higher risk of vasculopathy which can affect blood vessels supplying the optic nerve and retina. Conversely, VI may be a causal factor for obesity as poor vision may hinder or limit outdoor activities and physical exercises.

$\mathrm{ABI}$ is a biomarker for peripheral artery disease (PAD), including the risks of heart attack, stroke, or poor peripheral circulation $[42,53]$. To our knowledge, ABI has not been investigated for possible correlation with VI. We hypothesized that PAD is correlated with VI and investigated whether $A B I$ would differ among older adults with VI compared to those with normal vision, assuming that poor blood circulation has potential negative effect on visual health. Our result did not support this hypothesis but this may be because our sample size was too small.
We did not find VI to be associated with the onsite blood pressure measurement, self-reported history of hypertension or DM. A possible explanation is that we only examined the presence or absence of DM and hypertension, but did not examine their duration or severity, and consider the threshold effect or doseresponse relationship. One survey in eastern Taiwan showed that $>10$ years disease duration of $\mathrm{DM}$ and hypertension were independently associated with VI, whereas 10 years or less of disease duration was not [54]. Another survey in the United States showed that higher level of LDL-cholesterol was correlated with a higher risk for blindness [31].

Although hyperlipidemia was not significantly associated with unilateral VI, interaction term between hyperlipidemia and gender or between hyperlipidemia and obesity was statistically significant. In stratified analysis, among those having a history of hyperlipidemia, female suffered lower risk for unilateral VI than male while obese subjects suffered higher risk than non-obese subjects. Gender and obesity were more likely to have multiplicative effect on unilateral VI when they are present with hyperlipidemia.

Gender, hypertension and cataract were not associated with unilateral or bilateral VI in general population of pooled analysis, but stratified analysis showed that females was associated with lower risk for unilateral VI in hyperlipidemia subgroup; having a history of hypertension was associated with higher risk for unilateral VI in non-obese subgroup; and having a history of cataract was associated with higher risk for unilateral VI in hyperlipidemia subgroup and bilateral VI in non-obese subgroup. Conversely, obesity and hyperlipidemia were associated with bilateral VI in general population of pooled analysis, but stratified analysis showed that 
subjects being obese and having a history of hyperlipidemia were not associated with higher risk for bilateral VI in female or cataract subgroup. The findings showed that ORs varied in specific subgroups of stratified analysis. Risk factors identified in the general population may not be applicable to specific subgroups. Inversely, non-significant risk factors in the general population may be applicable to specific subgroups.

From the eye-level analysis, the significant association of VI with refractive error (myopia or hyperopia) showed that uncorrected refractive error remains a significant cause of impaired vision in this population. The associations with abnormal, suspicious, or undetermined cases of macula and optic disc appearance were not significant, suggesting their unpredictable or inconsistent effect on VA. Similarly, subjects' self-reported history of AMD, cataract or glaucoma was not significantly associated with VI. A possible explanation is that these were early cases or had received timely treatment for their condition which prevented significant visual loss. Another possible reason is that the sample size was small, resulting in wide confidence interval and biased results.

Our strength was that we investigated the visual health problems from a multi-perspective view. However, there were a few limitations. First, the sample size was relatively small, making subgroup analysis difficult. Second, since a free eye examination was provided, there may have been selection bias because people suffering from or interested in eye diseases were more likely to join our study. Third, the medical history was self-reported and may be affected by recall bias. Lastly, people with impaired ambulation from severe visual or physical disability may not have been assessed by our survey since we did not arrange household visits.

\section{Conclusions}

Spatial and temporal differences on the prevalence of bilateral VI were noted between our results and those from the previous survey by Lau et al. in 2002. Inequity of visual health was present, although the sampled community is considered a predominantly middle-class suburb. Subjects with older age, lower educational level, and/or living in temporary housing were vulnerable groups having higher risk for unilateral or bilateral VI. Obesity and hyperlipidemia were medical risk factors contributing to bilateral VI. Age was the confounders of the unilateral VI-hypertension, unilateral VI-educational level and bilateral VI-educational level relationships. Gender and obesity were more likely to have multiplicative effect on unilateral VI when combined with hyperlipidemia. Stratified analysis should be conducted to provide further insight into the risk factors for VI in specific populations, in addition to general population. Refractive error (myopia or hyperopia) was associated with VI in the eye-level analysis. We recommend conducting a larger, territory-wide survey of the elderly population in Hong Kong, to better assess the overall prevalence of VI and the effects of varying geographical locations.

\section{Supplementary information}

Supplementary information accompanies this paper at https://doi.org/10. 1186/s12886-020-01644-1.

Additional file 1: Table 6. Sociodemographic Profiles of Population in Chi Fu DCCA, Southern District, Shatin District and Hong Kong.

Additional file 2: Table 7. Characteristics of the 222 respondents in the study.

Additional file 3: Table 8. Prevalence of low vision, blindness and visual impairment by the 222 respondents from a southern suburb of Hong Kong in January 2016.

Additional file 4: Table 9. Epidemiologic factors associated with visual impairment by the 222 respondents from a southern suburb of Hong Kong in January 2016: Univariate logistic regression.

Additional file 5: Table 10. Associations of behavioural factors with medical risk factors among the 222 respondents.

Additional file 6: Table 11. Multiplicative interaction model for observing whether gender interacts with age, obesity, hypertension, hyperlipidemia or cataract on the risk for unilateral and bilateral VI.

Additional file 7: Table 12. Multiplicative interaction model for observing whether obesity interacts with age, gender, hypertension, hyperlipidemia or cataract on the risk for unilateral and bilateral VI.

Additional file 8: Table 13. Multiplicative interaction model for observing whether hypertension interacts with age, gender, obesity, hyperlipidemia or cataract on the risk for unilateral and bilateral VI.

Additional file 9: Table 14. Multiplicative interaction model for observing whether cataract interacts with age, gender, obesity, hypertension or hyperlipidemia on the risk for unilateral and bilateral VI.

Additional file 10: Questionnaire (original). Original traditional Chinese version.

Additional file 11: Questionnaire (translated). Translated English version

\section{Abbreviations}

ABI: Ankle-brachial index; AMD: Age-related macular degeneration; AORs: Adjusted odds ratios; BMl: Body Mass Index; Cls: Confidence intervals; CORs: Crude odds ratios; DCCAs: District Council Constituency Areas;

DM: Diabetes mellitus; EC: Ethics Committees; GLMM: Generalized linear mixed effects models; IQR: Interquartile range; IRB: Institutional Review Board: LDL: Low-density lipoprotein; logMAR: Logarithm of the Minimum Angle of Resolution; OCT: Optical coherence tomography; ORs: Odds ratios; PAD: Peripheral artery disease; QoL: Quality of life; RNFL: Retinal nerve fiber layer; VA: Visual acuity; VI : Visual impairment; WHO: World Health Organization

\section{Acknowledgements}

We would like to acknowledge Bayer Healthcare, Hong Kong Shun Lung Yan Chak Foundation, Novartis and The Eye Care Foundation for funding this study. Likewise, we would like to acknowledge Hong Kong Southern District Women's Association, Pok Fu Lam and Chi Fu Women's Association,

Southern District Council and Southern District Healthy \& Safe Association for their assistance. We would also thank those subjects who participated in our study.

\section{Authors' contributions}

IYHW designed the study and directed its implementation. JKPL supervised the fieldwork. BNKC, KCS, ALKN, IYHW, and JCHC contributed to eye 
examination. PWFW conducted statistical analysis and manuscript preparation. JCHC performed statistical analysis, reviewed the manuscript and made final approval of the version to be published. All authors confirmed that this manuscript has not been published, either in whole or in part, and is not in press or under review elsewhere. All authors approved the final manuscript and agreed with its submission to BMC Ophthalmology.

\section{Funding}

This work was supported by Bayer Healthcare, Hong Kong Shun Lung Yan Chak Foundation, Novartis and The Eye Care Foundation. The funders had no role in study design, data collection and analysis, decision to publish, or preparation of the manuscript.

\section{Availability of data and materials}

The datasets and computing code used during the current study are available from the corresponding author on reasonable request.

\section{Ethics approval and consent to participate}

Ethics approval of this study was granted by the Institutional Review Board (IRB) and Ethics Committees (EC) of the Hong Kong University / Hospital Authority Hong Kong West Cluster (reference number: UW 15-160) on 16th March 2015. All subjects agreeing to participate in the study gave their written, informed consent prior to the administration of any eye assessment or questionnaire.

\section{Consent for publication}

Not applicable.

\section{Competing interests}

The authors have no competing interest to declare.

\section{Received: 6 April 2020 Accepted: 14 September 2020} Published online: 18 September 2020

\section{References}

1. Li Y, Crews JE, Elam-Evans LD, Fan AZ, Zhang X, Elliott AF, et al. Visual impairment and health-related quality of life among elderly adults with age-related eye diseases. Qual Life Res. 2011;20(6):845-52

2. Chia EM, Wang JJ, Rochtchina E, Smith W, Cumming RR, Mitchell P. Impact of bilateral visual impairment on health-related quality of life: the Blue Mountains eye study. Invest Ophthalmol Vis Sci. 2004;45(1):71-6.

3. Black AA, Wood JM, Lovie-Kitchin JE. Inferior field loss increases rate of falls in older adults with glaucoma. Opt Vision Sci. 2011;88(11):1275-82.

4. Freeman EE, Munoz B, Rubin G, West SK. Visual field loss increases the risk of falls in older adults: the Salisbury eye evaluation. Invest Ophthalmol Vis Sci. 2007:48(10):4445-50.

5. Hong T, Mitchell P, Burlutsky G, Samarawickrama C, Wang JJ. Visual impairment and the incidence of falls and fractures among older people: longitudinal findings from the Blue Mountains eye study. Invest Ophthalmol Vis Sci. 2014;55(11):7589-93.

6. Lamoureux EL, Chong E, Wang JJ, Saw SM, Aung T, Mitchell P, et al. Visual impairment, causes of vision loss, and falls: the Singapore malay eye study. Invest Ophthalmol Vis Sci. 2008:49(2):528-33.

7. Vision Impairment and Comorbid Conditions. The United States: the Centers for Disease Control and Prevention; [updated 9 January 2018; cited 19 April]. Available from: https://www.cdc.gov/visionhealth/living/index.html.

8. Knudtson MD, Klein BE, Klein R. Age-related eye disease, visual impairment, and survival: the Beaver Dam Eye Study. Arch Ophthalmol. 2006;124(2):243-9.

9. Wang $\mathrm{CW}$, Chan $\mathrm{CL}, \mathrm{Ho} \mathrm{AH}$, Xiong Z. Social networks and health-related quality of life among Chinese older adults with vision impairment. J Aging Health. 2008;20(7):804-23.

10. Cumberland PM, Rahi JS. Visual function, social position, and health and life chances: the UK biobank study. JAMA Ophthalmol. 2016;134(9):959-66.

11. Wang CW, Chan CL. Psychosocial adaptation status and health-related quality of life among older Chinese adults with visual disorders. Qual Life Res. 2009;18(7):841-51.

12. Harutyunyan T, Giloyan A, Petrosyan V. Factors associated with visionrelated quality of life among the adult population living in Nagorno Karabagh. Public Health. 2017;153:137-46.
13. Khorrami-Nejad M, Sarabandi A, Akbari MR, Askarizadeh F. The impact of visual Impairment on quality of life. Med Hypothesis Discov Innov Ophthalmol J. 2016;5(3):96-103.

14. Cypel MC, Salomao SR, Dantas PEC, Lottenberg CL, Kasahara N, Ramos LR et al. Vision status, ophthalmic assessment, and quality of life in the very old. Arq Bras Oftalmol. 2017:80(3):159-64.

15. Lin JC, Yu JH. Assessment of quality of life among Taiwanese patients with visual impairment. J Formosan Med Assoc. 2012;111(10):572-9.

16. Chia EM, Mitchell P, Rochtchina E, Foran S, Wang JJ. Unilateral visual impairment and health related quality of life: the Blue Mountains eye study. $\mathrm{Br} J$ Ophthalmol. 2003;87(4):392-5.

17. Chia EM, Mitchell P, Ojaimi E, Rochtchina E, Wang JJ. Assessment of visionrelated quality of life in an older population subsample: the Blue Mountains eye study. Ophthalmic Epidemiol. 2006;13(6):371-7.

18. Wang $X$, Lamoureux $E$, Zheng $Y$, Ang M, Wong TY, Luo N. Health burden associated with visual impairment in Singapore: the Singapore epidemiology of eye disease study. Ophthalmology. 2014;121(9):1837-42.

19. Wang JJ, Mitchell P, Cumming RG, Smith W. Visual impairment and nursing home placement in older Australians: the Blue Mountains eye study. Ophthalmic Epidemiol. 2003;10(1):3-13.

20. Wang JJ, Mitchell P, Smith W, Cumming RG, Attebo K. Impact of visual impairment on use of community support services by elderly persons: the Blue Mountains eye study. Invest Ophthalmol Vis Sci. 1999;40(1):12-9.

21. Rein DB, Zhang P, Wirth KE, Lee PP, Hoerger TJ, McCall N, et al. The economic burden of major adult visual disorders in the United States. Arch Ophthalmol (Chicago, III : 1960). 2006;124(12):1754-60.

22. Koberlein J, Beifus K, Schaffert C, Finger RP. The economic burden of visual impairment and blindness: a systematic review. BMJ Open. 2013;3(11): e003471.

23. Wang W, Yan W, Muller A, Keel S, He M. Association of Socioeconomics with Prevalence of visual Impairment and blindness. JAMA Ophthalmol. 2017:135(12):1295-302.

24. Jimenez-Corona A, Jimenez-Corona ME, Ponce-de-Leon S, Chavez-Rodriguez M, Graue-Hernandez EO. Social determinants and their impact on visual Impairment in southern Mexico. Ophthalmic Epidemiol. 2015;22(5):342-8.

25. Katibeh M, Rajavi Z, Yaseri M, Hosseini S, Hosseini S, Akbarian S, et al. Association of socio-economic status and visual Impairment: a populationbased study in Iran. Arch Iran Med. 2017:20(1):43-8.

26. Tielsch JM, Sommer A, Katz J, Quigley H, Ezrine S. Socioeconomic status and visual impairment among urban Americans. Baltimore Eye Survey Research Group. Arch Ophthalmol (Chicago, III : 1960). 1991;109(5):637-41.

27. Ulldemolins AR, Lansingh VC, Valencia LG, Carter MJ, Eckert KA. Social inequalities in blindness and visual impairment: a review of social determinants. Indian J Ophthalmol. 2012;60(5):368-75.

28. Whillans J, Nazroo J. Social inequality and visual Impairment in older people. J Gerontol Ser B Psychol Sci Soc Sci. 2018;73(3):532-42.

29. Fan AZ, Li Y, Zhang $X$, Klein $R$, Mokdad AH, Saaddine JB, et al. Alcoho consumption, drinking pattern, and self-reported visual impairment. Ophthalmic Epidemiol. 2012;19(1):8-15

30. Zhang X, Kahende J, Fan AZ, Barker L, Thompson TJ, Mokdad AH, et al. Smoking and visual impairment among older adults with age-related eye diseases. Prev Chronic Dis. 2011;8(4):A84.

31. Steinman BA, Vasunilashorn S. Biological risk of older adults with visual impairments. J Nutr Health Aging. 2011;15(4):296-302.

32. Coreil J. Social and behavioral foundations of public health. Bryant CA Henderson JN, Forthofer MS, Quinn GP, editors. Thousand Oaks, Calif.: Sage Publications; 2001.

33. Michon JJ, Lau J, Chan WS, Ellwein LB. Prevalence of visual impairment, blindness, and cataract surgery in the Hong Kong elderly. Br J Ophthalmol. 2002:86(2):133-9.

34. Chong EW, Lamoureux EL, Jenkins MA, Aung T, Saw SM, Wong TY. Sociodemographic, lifestyle, and medical risk factors for visual impairment in an urban asian population: the singapore malay eye study. Arch Ophthalmol (Chicago, III : 1960). 2009;127(12):1640-7

35. 2016 Population By-census. Hong Kong: census and statistics department, HKSAR government; [updated 15 march 2018; cited 17 April 2018]. Available from: https://www.bycensus2016.gov.hk/en/index.html.

36. Johnson GJ. The epidemiology of eye disease. 3rd ed. ed. London : Hackensack, NJ: Imperial College Press : Distributed by World Scientific; 2012

37. Marmamula S, Khanna RC, Rao GN. Unilateral visual impairment in rural South India-Andhra Pradesh eye disease study (APEDS). Int J Ophthalmol. 2016;9(5):763-7. 
38. Lam CS, Lam CH, Cheng SC, Chan LY. Prevalence of myopia among Hong Kong Chinese schoolchildren: changes over two decades. Ophthal Physiol Optics. 2012;32(1):17-24.

39. Body Mass Index (BMI) Distribution. Hong Kong: Department of Health; [updated 04 January 2018; cited 03 July 2018]. Available from: https://www. chp.gov.hk/en/statistics/data/10/280/427.html.

40. BMI classification. Switerland: World Health Organization (WHO); [updated 03 July 2018; cited 03 July 2018]. Available from: http://apps.who.int/bmi/ index.jsp?introPage=intro_3.html.

41. Appropriate body-mass index for Asian populations and its implications for policy and intervention strategies. Lancet (London, England). 2004; 363(9403):157-63.

42. Ankle-brachial index. The United States: Mayo Clinic; [updated 10 January 2016; cited 03 July 2018]. Available from: https://www.mayoclinic.org/testsprocedures/ankle-brachial-index/about/pac-20392934.

43. Blood pressure chart. The United Kingdom: Blood Pressure UK; [cited 03 July 2018]. Available from: http://www.bloodpressureuk.org/ BloodPressureandyou/Thebasics/Bloodpressurechart.

44. High blood pressure (hypertension). The United Kingdom: The National Health Service (NHS); [updated 15 June 2016; cited 03 July 2018]. Available from: https://www.nhs.uk/conditions/high-blood-pressure-hypertension/.

45. He Y. Missing data analysis using multiple imputation: getting to the heart of the matter. Circ Cardiovasc Qual Outcomes. 2010;3(1):98-105.

46. Sterne JA, White IR, Carlin JB, Spratt M, Royston P, Kenward MG, et al. Multiple imputation for missing data in epidemiological and clinical research: potential and pitfalls. BMJ (Clinical research ed). 2009:338:b2393.

47. R Core Team. R: A language and environment for statistical computing. Vienna: R Foundation for statistical Computing; [2018]. Available from: https://www.r-project.org/.

48. Rim TH, Nam JS, Choi M, Lee SC, Lee CS. Prevalence and risk factors of visual impairment and blindness in Korea: the fourth Korea National Health and nutrition examination survey in 2008-2010. Acta Ophthalmol. 2014; 92(4):e317-25.

49. Pan CW, Qian DJ, Sun HP, Ma Q, Xu Y, Song E. Visual Impairment among older adults in a rural Community in Eastern China. J Ophthalmol 2016; 2016:9620542

50. Marmamula S, Narsaiah S, Shekhar K, Khanna RC, Rao GN. Visual impairment in the south Indian state of Andhra Pradesh: Andhra Pradesh - rapid assessment of visual impairment (AP-RAVI) project. PLoS One. 2013;8(7): e70120

51. Liu JH, Cheng CY, Chen SJ, Lee FL. Visual impairment in a Taiwanese population: prevalence, causes, and socioeconomic factors. Ophthalmic Epidemiol. 2001;8(5):339-50.

52. Ong SR, Crowston JG, Loprinzi PD, Ramulu PY. Physical activity, visual impairment, and eye disease. Eye (London, England). 2018.

53. Khan TH, Farooqui FA, Niazi K. Critical review of the ankle brachial index Curr Cardiol Rev. 2008;4(2):101-6.

54. Wang WL, Chen N, Sheu MM, Wang JH, Hsu WL, Hu YJ. The prevalence and risk factors of visual impairment among the elderly in eastern Taiwan. Kaohsiung J Med Sci. 2016:32(9):475-81.

\section{Publisher's Note}

Springer Nature remains neutral with regard to jurisdictional claims in published maps and institutional affiliations.

Ready to submit your research? Choose BMC and benefit from:

- fast, convenient online submission

- thorough peer review by experienced researchers in your field

- rapid publication on acceptance

- support for research data, including large and complex data types

- gold Open Access which fosters wider collaboration and increased citations

- maximum visibility for your research: over $100 \mathrm{M}$ website views per year

At $\mathrm{BMC}$, research is always in progress.

Learn more biomedcentral.com/submissions 